WINPEC Working Paper Series No.E1903

April 2019

Vulnerability of Fixed-Rate Funds-Supplying Operations to Overbidding: An Experimental Approach

Yukihiko Funaki, Junnosuke Shino and Nobuyuki Uto

Waseda INstitute of Political EConomy

Waseda University

Tokyo, Japan 


\title{
Vulnerability of Fixed-Rate Funds-Supplying Operations to Overbidding: An Experimental Approach *
}

\author{
Yukihiko Funaki
}

\author{
Junnosuke Shino $\ddagger$
}

April 8, 2019

\author{
Nobuyuki Uto $\$$
}

\begin{abstract}
This paper experimentally investigates overbidding in the fixed-rate funds-supplying operations conducted by central banks. One motivation for this is that while the European Central Bank had experienced severe overbidding in the conduct of its fixed-rate operations, no comparable behavior has been observed for the Bank of Japan. Existing theoretical analyses argue that this is because the currently accommodative financial environment in Japan has made bidders' objective functions locally satiated, and this contributes to the avoidance of overbidding. To investigate this further, we conduct an experiment with fixedrate operations, the results of which are as follows. When participants' initial demands are sufficiently small, they simply play the unique Nash equilibrium strategy to bid their true demand. Further, as demand increases and there is no satiation in their objective functions, participants tend to overbid. However, even as demand becomes larger, an explosion of bids does not arise if the objective functions are sufficiently satiated. We also estimate the subject bid functions from the experimental data affected by the degree of satiation and reveal that a simple calibration points to the vulnerability of fixed-rate operations to overbidding, even when satiation is preserved.
\end{abstract}

Keywords: Fixed-rate funds-supplying operations; Overbidding; Experiments

\section{Introduction}

\subsection{The Bank of Japan's fixed-rate funds-supplying operations}

In December 2009, the Bank of Japan (BOJ) introduced a new framework of market operation known as a fixed-rate funds-supplying operation against pooled collateral (hereafter fixed-rate operation) to address the turmoil in international financial markets current at the time ${ }^{1}$.

*The authors would like to thank Charles Noussair, Yoshio Kamijo, and conference participants at the 2018 BEAM-ABEE workshop on "Experimental and Behavioral Analyses in Macroeconomics and Finance", held at the University of Amsterdam, Netherlands and the 2019 East Asia Game Theory International Conference held in Fuzhou, China for their helpful comments and suggestions.

${ }^{+}$School of Political Science and Economics, Waseda University, 1-6-1 Nishiwaseda, Shinjuku-ku, Tokyo, Japan 169-8050; funaki@waseda.jp

$\ddagger$ School of International Liberal Studies, Waseda University, 1-6-1 Nishiwaseda, Shinjuku-ku, Tokyo, Japan 169-8050; junnosuke.shino@waseda.jp

§Faculty of Economics and Management, Hokuriku University, 1-1 Taiyogaoka, Kanazawa-shi, Ishikawa, Japan 920-1180; nobuyuki.uto@gmail.com

${ }^{1}$ The following description of this framework draws on BOJ [4] and Shino [16]. Funds-supplying operations are operations in which the BOJ extends loans to its counterparties, with pooled collateral submitted by these counterparties to the bank backing these loans. These operations are very convenient for the counterparties because a wide range of assets, including government bonds, other public liabilities, and corporate debt such as corporate bonds and commercial paper, are eligible to be used as collateral. The counterparties can also easily substitute different kinds of collateral. For its part, pooled collateral refers to collateral that the counterparties submit to the BOJ based on agreements pertaining to transactions with it, such as funds-supplying operations against pooled collateral, complementary lending facilities, and intraday overdrafts and other contracts. 
The fixed-rate operations take the form of loans, with the loan rates presumably fixed at the BOJ's target for the uncollateralized overnight call rate stipulated in the guidelines for money market operations. Because the BOJ announces the total amount of funds supplied for each auction in advance, the rate and amount applied to each auction are common knowledge among bidders. Given this, every participant simply bids the amount of money they wish to obtain at that rate. If the sum of all bids is equal to or smaller than the total allotment preannounced by the BOJ (the case of "undersubscription"), then each bidder receives the amount of money for which it bids. Otherwise, the allotment is proportionally allocated depending on the supplied bids.

Starting from December 10, 2009, the BOJ offered 800 billion yen per operation with a term of three months and conducted the auction about once a week until the middle of March 2010 (Fig.1). The cumulative amount outstanding from these operations reached around 10 trillion yen by the end of February 2010. Subsequently, at the MPM (Monetary Policy Meeting) held on March 16 and 17, 2010, the BOJ decided to increase the frequency of the fixed-rate operations to twice weekly, and as a result, the amount outstanding from these operations rose to about 20 trillion yen by June 2010. Furthermore, at an unscheduled MPM on August 30, 2010, the BOJ introduced a six-month term in its fixed-rate operations to encourage a fall in market interest rates. The BOJ began this process by providing additional funding of approximately 10 trillion yen with a six-month term, while maintaining the outstanding amount of funds provided by the existing three-month term operations at 20 trillion yen. At the MPM on August 4, 2011, as a way of further enhancing monetary easing to ensure the successful transition to recovery following the Great East Japan Earthquake and a sustainable growth path, the BOJ increased the outstanding amount of funds for the six-month term from 10 to 15 trillion yen, while leaving that for the three-month term unchanged at 20 trillion yen.

On April 27, 2012, the BOJ made the decision to increase the total size of the "Asset Purchase Program" introduced in October 2010 in which the outstanding amount of fixed-rate operations was included by about 5 trillion yen $(65 \rightarrow 70$ trillion yen). However, while asset purchasing for Japanese government bonds and exchange-traded funds increased, the maximum outstanding amount for the 6-month fixed-rate operations fell by about 5 trillion yen (15 $\rightarrow 10$ trillion yen), after taking into account episodes of substantial undersubscription. Furthermore, at the MPM on July 12, 2012, to address the observed undersubscriptions, the policy board decided to (i) reduce the maximum outstanding amount for the fixed-rate operation by about 5 trillion yen, and (ii) integrate loan durations ("3 months" and "6 months") into "within 6 months" to respond flexibly to liquidity demand by financial institutions. As a result, the total maximum amount for the operation was set to about 25 trillion yen.

When the Quantitative and Qualitative Monetary Easing Policy (QQE) was introduced in April 2013, the target outstanding amount of the fixed-rate operation was abolished with the ending of the Asset Purchase Program ${ }^{2}$. Reflecting the BOJ's ample provision of funds to financial markets through large-scale purchases of a wide range of assets conducted under

\footnotetext{
${ }^{2}$ The following description is largely from the BOJ [5].
} 
QQE, perceptions of abundant liquidity became extremely strong in the money markets.

Figure 1: Implementation of the BOJ's fixed-rate operations

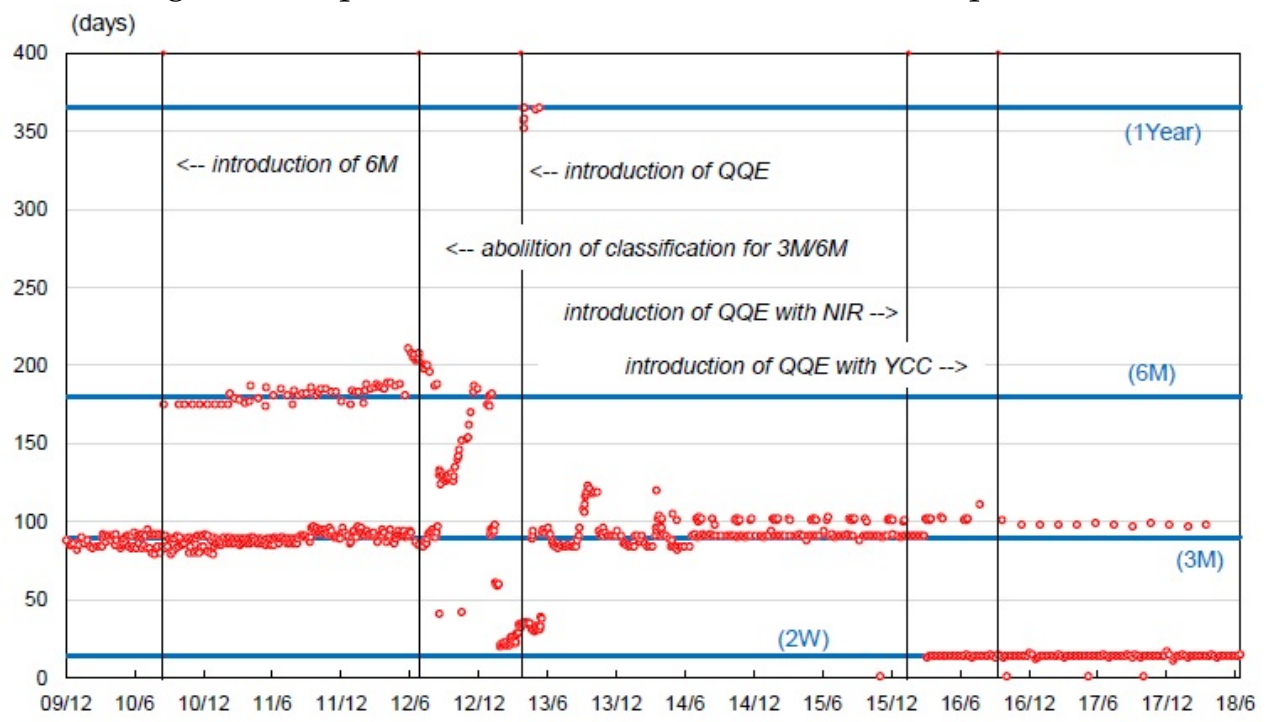

Notes: 1. Each dot corresponds to the implementation of a fixed-rate funds-supplying operation. The vertical axis indicates the duration of operation.

2. The five vertical lines in the figure indicate: (1) the introduction of 6-month operations (August 2010), (2) the integration of the 3- and 6-month operations into the "within 6-month" operations (July 2012), (3) the introduction of the Quantitative and Qualitative Monetary Easing Policy (QQE, April 2013), (4) the introduction of QQE with negative interest rate policy (QQE with NIR, January 2016), and (5) the introduction of QQE with Yield Curve Control (QQE with YCC, September 2016), respectively from the left.

After the QQE with Negative Interest Rate Policy (NIR) was introduced in January 2016, the $\mathrm{BOJ}$ offered operations with the interest rate reduced to 0 percent per annum from the previous 0.1 percent. In addition, given the growing needs among financial institutions to fine tune their current account balances, starting from the middle of March 2016, the BOJ changed the operation from an offer of 800 billion yen with a 3-month term to that with a 2-week term. Under the current policy framework of QQE with Yield Curve Control (YCC), introduced in September 2016, the BOJ has continued to offer fixed-rate operations with a two-week term at the rate of 800 billion yen per operation once a week and those with about a 100-day term at the rate of 500 billion yen per operation once every seven weeks. All of these operations are offered with a fixed interest rate of 0 percent.

\subsection{Bidding patterns in fixed-rate operations: ECB and BOJ}

Since their introduction, the fixed-rate operations have become one of the BOJ's main fundssupplying measures. However, it is not the first time that this type of operation has served as a funds-supplying tool for a central bank ${ }^{3}$. Indeed, until June 21, 2000, the European Central Bank's (ECB) main refinancing operations were conducted as fixed-rate tenders. In

\footnotetext{
${ }^{3}$ Ewerhart et al. [10] provide a detailed survey of the uses of fixed-rate tenders in the Euro area and the United Kingdom.
} 
these operations, it is well known that severe overbidding (total bids drastically exceed the total allotment offered by the ECB) was observed, with the bid-to-cover ratio (the total amount of bids/the amount of funds provided) typically having a value exceeding $100^{4}$.

One possible explanation for this overbidding was that expectations of an interest rate hike in the near future were heightened, and this enhanced the relative attractiveness of fixed-rate operations as ECB [9] indicates. However, it was also pointed out that at the time the bid-tocover ratio had continuously and steadily increased independent of changes in expectations regarding future interest rate hikes.

To clarify a mechanism for the overbidding, Nautz and Oechssler [14] provide a simple game-theoretic model called the repo game. The environment that the game describes is as follows ${ }^{5}$. A financial institution participating in a fixed-rate operation is considered to have some initial demand for the auction based on the demand for reserve requirements or for daily cash management. If the actual allotment exceeds the initial demand, an opportunity cost is then incurred through the holding of excess reserves. Meanwhile, under the condition where the interest rate applied to a fixed-rate operation is lower than market interest rates, the difference in these rates will also become a cost if the actual allotment is less than the initial demand. Therefore, the objective function of a bidder can be expressed as a convex loss function that attains a minimum value of zero when the actual allotment equals the initial demand. Based on this environment, now take a bidder A and suppose that all bidders other than A bid their initial demand and the sum of their bids exceeds the total allotment offered by the central bank. Then A's actual quota is equal to A's bids multiplied by the allotment ratio, which is strictly less than one. Therefore, for A's actual quota to equal A's initial demand, A must bid more than its initial demand. If so, then letting $x$ be an allotment ratio when all bidders choose their initial demand, the allotment ratio is lower than $x$ (when [a] A bids greater than its initial demand and $[\mathrm{b}]$ all other bidders other than A are assumed to truthfully announce their own initial demand). Furthermore, as bidders assume a lower allotment ratio in the next period, they will choose larger bids. Ultimately, through the continuation of this process, the bid-to-cover ratio explodes. This yields the basic mechanism underpinning the overbidding according to the repo game.

However, a striking fact regarding the implementation of the BOJ's fixed-rate operations is that the bid-to-cover ratio has instead remained stable and has not demonstrated any of the surges found in the ECB's operations (Fig.2). As factors that could potentially contribute to such developments, Shino [16] points out the level of interest rates applied to the complementary deposit facility and the recent accommodative financial environment in Japan. First, by paying interest on excess reserve balances, the facility has the effect of reducing the opportunity cost of holding excess reserves when the actual allotment is larger than the initial demand. Next, under a situation in which market interest rates remain at an extremely low level, the external funding cost is sufficiently small when the actual allotment is smaller than the initial demand. Consequently, we can consider the cost as zero as long as the difference between the initial

\footnotetext{
${ }^{4}$ See, for example, Fig. 1 of Nautz and Oechssler [14].

${ }^{5}$ The following description draws on the BOJ [4].
} 
demand and the actual allotment remains in a certain range. With such a satiated objective function, we can then show that bidding the same amount as that in the previous period is the best response. Therefore, bid-to-cover ratios that remain within a certain range can be supported by an equilibrium. Shino [16] also demonstrates that there is an empirically identifiable relationship between the bid-to-cover ratio and an accommodative financial environment. However, this equilibrium analysis supports not only the stable bid-to-cover ratios currently observed in Japan but also the overbiddings. That is, the analysis contains the challenge of multiple equilibria. Therefore, the above empirical result may only suggest the possibility that a satiated objective function could be one of the factors influencing bidding patterns.

Figure 2: Bid-to-cover ratio under the BOJ's operations

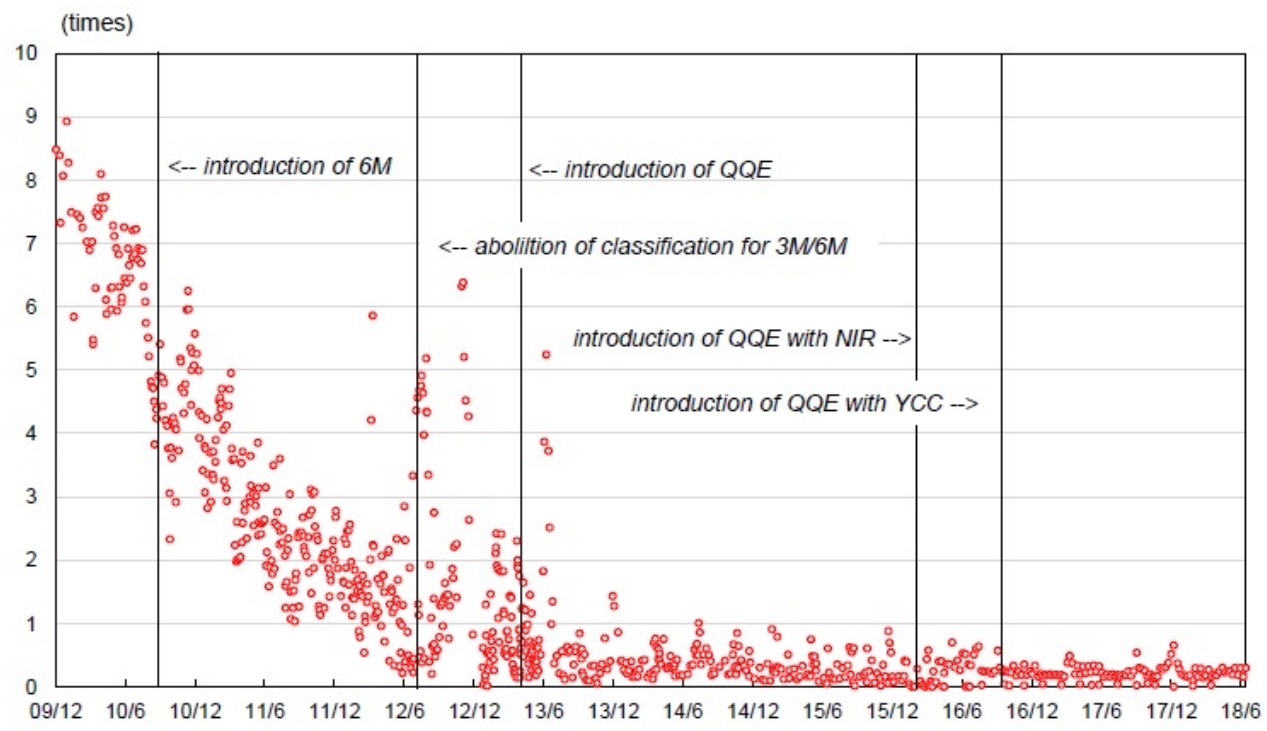

Notes: Each dot indicates the bid-to-cover ratio (the total amount of bids/the amount of funds provided) in a fixed-rate operation. The events indicated by the five vertical lines are identical to those in Fig.1.

Accordingly, in this paper, we conduct an experiment with fixed-rate funds-supplying operations to examine whether a satiated objective function has the effect of preventing the bid-to-cover ratio from exploding. We also wish to identify subject bidding behavior in these sorts of operations. The experiment environment is essentially the same as the above repo game, and a satiated objective function will be where the degree of satiation changes over the periods assigned to each subject. The total amount of funds provided and the lending rates are preannounced, and each subject simply bids the amount of money. The experiment illustrates several intriguing results, including those not readily clarified by existing analyses as follows: (1) when participants' initial demands are sufficiently small, they simply play the unique Nash equilibrium strategy of bidding their true demand; (2) as the demands become large and no satiation exists in their objective functions, participants are likely to overbid. However, (3) even with a larger demand, the explosion of the bids does not occur when the objective functions are sufficiently satiated. Moreover, we (4) estimate bid functions in which the degree of satiation influences the bids through their utility functions and (5) argue that there is a vulnerability of 
fixed-rate operations to overbidding even when satiation is preserved through implementing a simple calibration based on the estimated bid functions.

\subsection{Related literature}

To our knowledge, our analysis is the first experimental approach to examine bidding patterns in central bank funds-supplying operations. The following literature directly relates to our analysis.

To start, our analysis obviously relates to theoretical and empirical analyses concerning the fixed-rate operations of central banks. In terms of theoretical analysis, in addition to Nautz and Oechssler [14], Ayuso and Repullo [2] model fixed-rate tenders conducted by the ECB in its open market operations and describe overbidding as a unique equilibrium under an asymmetric objective function of the central bank. Later, Ewerhart et al. [10] theoretically identify that the extent of overbidding is heavily influenced by exposure risk i.e., the risk of receiving an overly large allotment. Elsewhere, Catalao-Lopes [8] compares fixed-and variable-rate tenders using a game-theoretic framework and concludes that overbidding is inherent to fixed-rate tenders, but very mitigatable under a variable-rate procedure, and that unlike fixed-rate tenders, variablerate tenders allow the keeping of some of the informational content of quantity bids. As for empirical approaches to fixed-rate operations, Ayuso and Repullo [1], using both individual and aggregate bidding data, provide empirical evidence that overbidding in fixed-rate tenders is attributable to the liquidity allotment decisions of the ECB, not to the expectations of a future tightening of monetary policy. Conversely, Breitung and Nautz [7], identify a positive relation between the bid-to-cover ratio and market interest rates in the ECB's repo auctions. Lastly, Nautz and Oechssler [15] empirically investigate various theories explaining overbidding in fixed-rate tenders by the ECB and conclude none fully explain actual overbidding on their own, such that existing measures to improve the efficiency of the operational framework would not eliminate overbidding.

Next, it should be noted that the allocation mechanism for fixed-rate operations is essentially the same as rationing in a fixed-price market. In this regard, Grimm et al. [11] examine a fixedprice allocation mechanism where bidders are proportionally rationed if aggregate demand exceeds aggregate supply, and show that while overbidding can be theoretically supported, participants tend to change the degree of overbidding depending on the price level. In related work, Bierbaum and Grimm [6] characterize an equilibrium of a fixed-price mechanism for the problem of selling shares of a divisible good to a large number of buyers when demand is uncertain and find that bidders have an incentive to overstate their demand in a fixed-price mechanism.

Finally, at first impression, we include this paper as an experimental analysis of auction theory. However, in fixed-rate funds-supplying auctions, the price (= preannounced interest rate) is fixed and the allotment is proportionally allocated depending on the bids. Therefore, unlike conventional funds-supplying operations with variable-rate tenders, it may not be appropriate 
to analyze these fixed-rate operations using standard auction theory ${ }^{6}$.

The remaining part of the paper is organized as follows. Section 2 reviews the theoretical analyses of fixed-rate operations and Section 3 describes the design of the experiment. Section 4 shows the main results, including graphical sketches of the bids, some hypothesis testing, the estimation of the bidding functions under the subjects' locally satiated objective functions, and a simple calibration to examine the effects of changes in the degree of satiation. Section 5 concludes.

\section{Theoretical Background of Overbidding and Stable Bids in Fixed- rate Operations}

We first review the structure of the repo game proposed by Nautz and Oechssler [14]. Let $\{1,2, \ldots, n\} \equiv N$ be the set of financial institutions, each of which is a participant in a fixed-rate auction, where $i \in N$ has its initial demand $d_{i}$. The game commences with the central bank's announcement of the total allotment of funds $a$ and a fixed lending rate $r$. Given $a$ and $r$, each bidder $i$ chooses the amount of bids denoted by $b_{i}$. Once $b=\left(b_{1}, \ldots, b_{n}\right) \in B$ is determined, the allotment ratio, defined by $q \equiv \operatorname{Min}\left\{\frac{a}{\sum_{j \in N} b_{j}}, 1\right\}$ is computed. We also let $\beta=\frac{\sum_{j \in N} b_{j}}{a}$ be a bidto-cover ratio. Overbidding indicates a process where $\beta$ significantly exceeds 1 and continues to increase. Finally, the actual allotment to bidder $i$, denoted $a_{i}$, is determined by $a_{i}=q b_{i}$. That is, if the sum of all bids exceeds the total allotment $a$, the actual allotment to $i$ is proportionally allocated depending on the ratio of $i$ 's bid to all bids.

Because bidders choose their actions simultaneously, there is strategic uncertainty and bidders are assumed risk averse. Specifically, we start with the following quadratic singlepeaked loss function that bidder $i$ minimizes $L_{i} \equiv\left(a_{i}-d_{i}\right)^{2}$ (See Fig.3).

Figure 3: A bidder's loss function in a normal financial environment

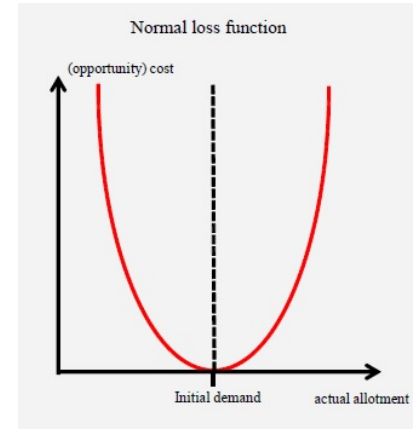

With this setup, Nautz and Oechssler [14] show the following.

\section{Remark 2.1 (Nautz and Oechssler [14])}

1. If $a \geq \sum_{j \in N} d_{j}$, then $\left[b_{i}=d_{i} \forall i \in N\right]$ is the Nash equilibrium.

${ }^{6}$ For a comprehensive survey of the experimental approaches to auctions, see Kagel and Roth [12] and Lusk and Shogren [13]. 
2. If $a<\sum_{j \in N} d_{j}$, no Nash equilibrium exists.

While the first case corresponds to undersubscription, the second statement cannot explain any actual bidding behavior. To describe the overbidding observed under ECB operations, Nautz and Oechssler [14] introduce a Myopic Best-Reply Process (MBR), an assumption regarding participants' bidding behavior such that each bidder has adaptive expectations.

More specifically, consider a series of periods $t=1,2, \ldots$ and a strategy profile at $t$ denoted by $b_{t}=\left(b_{1, t}, \ldots, b_{n, t}\right)$. Hereafter, subscript $t$ is explicitly stated depending on its necessity. Now suppose that $\sum_{j \in N} d_{j, t}>a_{t}$ and $b_{i, t}=d_{i, t}$ for all $i \in N$, that is, at $t$ each $i$ simply bids its initial demand $d_{i, t}$. The MBR process assumes that at $t+1$ bidder $i$ chooses the best response to $b_{-i, t} \equiv\left(b_{1, t}, \ldots, b_{i-1, t}, b_{i+1, t}, \ldots, b_{n, t}\right)$, based on the adaptive expectation that at $t+1$ all bidders other than $i$ would continue to bid the same amounts as those at $t$. As the actual allotment to $i$ at $t$ is strictly smaller than its initial demand $\left(a_{i, t}<d_{i, t}\right), i^{\prime}$ s bid at $t+1$ satisfies, based on MBR, $b_{i, t+1}>b_{i, t}$. That is, once the sum of the bids exceeds $a_{t}$ (true given $\sum_{j \in N} b_{j, t}=\sum_{j \in N} d_{j, t}>a_{t}$ ), the process continues to explode for certain. This is the overbidding mechanism argued by Nautz and Oechssler [14].

Conversely, and as mentioned earlier, the bid-to-cover ratio under the BOJ's fixed-rate operations has remained stable and has not yet displayed the surges observed in the ECB's operations (Fig.2). Shino [16] presents some possible reasons, including (1) the recent accommodative financial environment in Japan and (2) the level of interest rates applied to the complementary deposit facility ${ }^{7}$ contribute to the stable evolution of the bid-to-cover ratio because they together make the cost remain zero as long as the gap between the actual allotment and the initial demand $\left(=a_{i, t}-d_{i, t}\right)$ remains within a certain range. To subsume these factors, Shino [16] introduces the following locally satiated loss function into the repo game ( equation (1) and Fig.4 ), and provides the following remark.

$$
\tilde{L}_{i}=\left\{\begin{array}{ccc}
0 & \text { if } & d_{i}-k \leq a_{i} \leq d_{i}+k \\
\left(a_{i}-d_{i}\right)^{2} & \text { if } & a_{i}<d_{i}-k \text { and } d_{i}+k<a_{i}
\end{array}\right.
$$

Figure 4: A bidder's locally satiated loss function

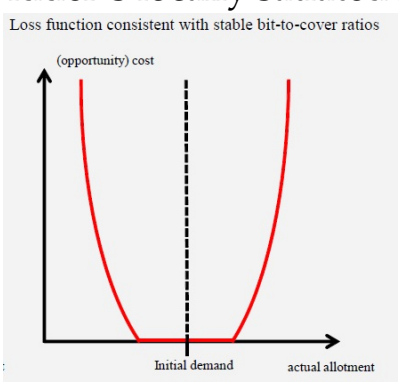

\footnotetext{
${ }^{7}$ The BOJ introduced the complementary deposit facility in Oct. 2008 as a means to pay interest on the excess reserves held by financial institutions. For details, see BOJ [3].
} 


\section{Remark 2.2 (Shino [16])}

Suppose $a<\sum_{j \in N} d_{j}$ and each bidder $i$ has a loss function $\tilde{L}_{i}$ as expressed in (1). Then there exists $\tilde{k}$ such that if $k \geq \tilde{k}$, then any bid-to-cover ratio that is neither overbidding nor undersubscription can be supported by a Nash equilibrium.

Remark 2.2 means that in the situation where a bidder's loss function is satiated, then the stable bid-to-cover ratio currently observed under the BOJ's fixed-rate auction can be described as a Nash equilibrium. However, while this result may suffice as a descriptive analysis of bidding behavior in fixed-rate operations, the satiated objective function supports not only an equilibrium consistent with a stable bid-to-cover ratio but also one with overbidding. Therefore, it is worth implementing an experiment with fixed-rate operations to examine whether a satiated objective function has the power to prevent the ratio from exploding as well as identifying the subjects' bid functions and deriving useful policy implications.

\section{The Experimental Design}

In what follows, we describe the experimental design where we assign subjects a specific objective function (described below) and play a symmetric repo game.

The experiment involves two "sessions" (or "scenarios") and each scenario has 34 periods. In each period, bidder $i$, being assumed to attend a fixed-rate operation, plays a five-person simultaneous game, essentially a repo game with or without satiation in their objective functions. There are six teams playing the game in a period, and thus there are 30 subjects playing a repo game in each scenario.

We fix the amount of liquidity provided in a game at $a_{t}=2000$ for every period $t$ and for both scenarios. At $t$, bidder $i$ chooses an amount of bid denoted $b_{i, t}$. Letting $B_{i, t}$ be $i$ 's set of strategies at $t$, we assume $\left.B_{i, t}=\left\{b_{i, t} \mid b_{i, t} \in[0,2000]\right\}\right)$. We impose a maximum bidding limit of 2000, which can be considered as sufficiently large in that the limit is identical to the total liquidity provision $a_{t}$. Let $a_{i, t}$ be the actual allotment to $i$ at $t$.

In our setting, (i) bidders' initial demands and (ii) the degree of satiation in their objective functions are time dependent. First, as initial demands, we assume symmetry in that the demand is identical among all bidders in each period, with the demand denoted $d_{t}$. The evolutions of $d_{t}$ are also assumed identical for Scenarios 1 and 2, as described in Fig. 5. $d_{t}$ starts with small numbers (100) at $t=1$ so that the sum of the demands of all bidders (500) is substantially smaller than the total amount of provided funds (2000) in a fixed-rate operation. This continues to hold until $t=6$, and at $t=7$ the sum becomes equal to 2000. After $t=8, d_{t}$ is fixed at 500, meaning the sum of demands exceeds $a_{t}=2000$, suggesting the vulnerability to overbidding as long as there is no satiation in the subjects' objective functions.

One of the intriguing features of our setup is that the degree of satiation represented by $k$ in equation (1) changes over the periods (therefore we hereafter include the subscript $t$ ). In terms of a comparison with the actual conduct of monetary policy, an increase (decrease) in $k_{t}$ corresponds to monetary easing (tightening or normalization). Fig.6 illustrates the evolution of 
the sequences of $k_{t}$ for each scenario. Initially, $k_{t}$ is set to zero and remains at this level by period 10 , that is, no satiation exists. Then from $t=11$ onwards, $k_{t}$ increases by 100 in each period and attains 400 at $t=14$. After this, both scenarios enter a "normalization" phase in which the degree of satiation becomes gradually weaker and $k_{t}$ returns to 0 . The difference between the two scenarios is the "speed" of normalization. As shown in Fig.6, the speed of normalization for Scenario 1 is faster than that in Scenario 2 such that normalization is "completed" $\left(k_{t}=0\right)$ at $t=20$ in Scenario 1, but at $t=23$ in Scenario 2. After the first cycle of the increase and decrease in the degree of satiation, both scenarios then enter the second cycle. In the second cycle, the speed of normalization becomes inverse between the two scenarios.

Figure 5: Evolution of $d_{t}$

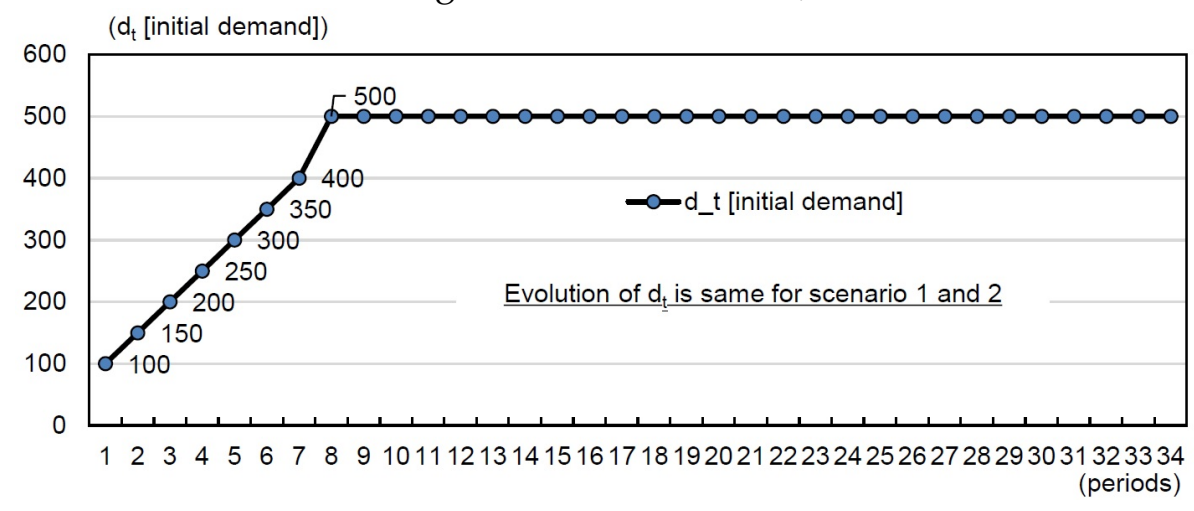

Figure 6: Evolution of $k_{t}$

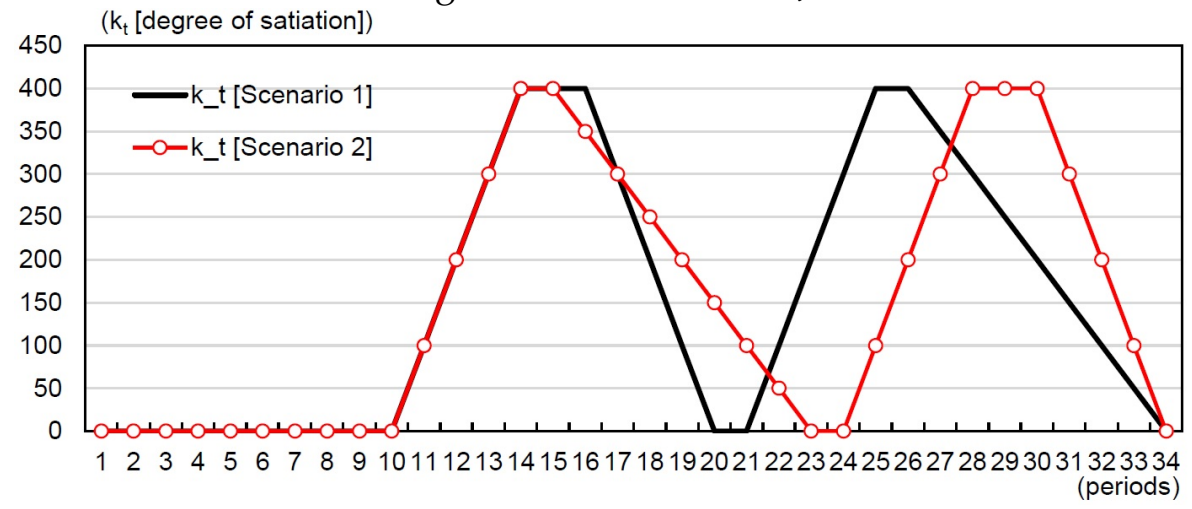

The experiment shuffles all of the subjects and rearranges the members of the teams twice over the periods. The aim of this is to exclude possible "history effects," i.e., once a subject tends to choose a large bid, overbidding would prevail in all subsequent periods. The timings of the shuffles are: (i) the 8th and 21st periods for Scenario 1, and (ii) the 8th and 24th periods for Scenario 2.

Finally, we specify the subjects' objective function. Instead of the loss functions in the theoretical analysis in Nautz and Oechssler [14] and Shino [16], we adopt utility functions in 
which each subject aims to maximize the level of utility. This is because we expect the subjects to find it easier to understand their own objective function and to compute any payoffs. We define the utility function as follows (equation (2) and Fig.7 ):

$$
u_{i, t}\left(b_{i, t}, b_{-i, t} ; a, d_{t}, k_{t}\right)=\left\{\begin{array}{cl}
\left(d_{t}+k_{t}\right)-a_{i, t}+500(<500) & \text { if } d_{t}+k_{t}<a_{i, t} \\
500 & \text { if } d_{t}-k_{t} \leq a_{i, t} \leq d_{t}+k_{t} \\
a_{i, t}-\left(d_{t}-k_{t}\right)+500(<500) & \text { if } a_{i, t}<d_{t}-k_{t}
\end{array}\right.
$$

Figure 7: The utility function assigned to subjects in the experiments

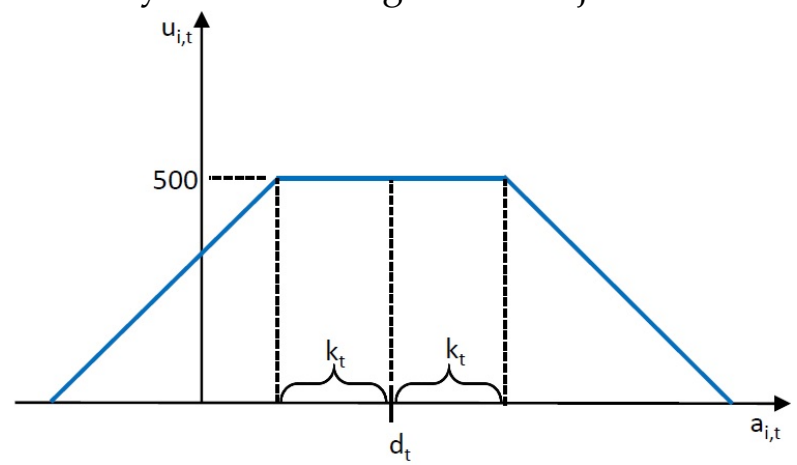

As shown in Fig.7, we further assume the utility function is linear-kinked rather than quadratic as in the theoretical analyses. Once again, this is because the computation of the payoffs will become much easier for the subjects. It is also obvious that all of the theoretical results shown in previous sections hold with a linear-kinked utility function.

Bidder $i$ obtains the maximum utility (set to 500), as long as the actual allotment $a_{i, t}$ lies in the range of $\left[d_{t}-k_{t}, d_{t}+k_{t}\right]$. Therefore, recalling the satiated loss function $L_{i}$ defined in (1), $u_{i}(\cdot)=500-L_{i}(\cdot)$ in this case. Once $a_{i, t}$ is outside this range, the level of utility linearly decreases, and the amount of decrease becomes large when $a_{i, t}$ is outside the range. See the example below.

We conducted all of the experiments at Waseda University in July 2015. The participants comprised 60 students drawn from the various majors at the university and recruited through a website restricted to Waseda University students. At the beginning of the computer-based experiment, participants were randomly assigned to booths in a lab, the instructions were then read aloud, and then the participants performed each task. Each participants received around 2,000 Japanese Yen (= about 20 U.S. dollars) on average.

\section{An example of the utility function}

Assume $a=2000, d_{t}=500, k_{t}=300$ and the bidding profile is represented by the column for " $b_{i, t}$ " in the table in Fig.8. The actual allotment and the level of utility obtained for each $i$ are shown in columns $a_{i, t}$ and $u_{i, t}$, respectively. Because a relatively strong degree of satiation exists in this numerical example, bidder $i$ obtains the maximum utility 500 as long as $a_{i, t}$ satisfies $200 \leq a_{i, t} \leq 800$. Bidders $1,2,3$, and 5 also satisfy this condition, while bidder 4 only receives 
362.5 because $a_{i, t}=62.5$. The graphical image of the utility function in this numerical example is also shown in Fig.8.

Figure 8: An example of the utility function

\begin{tabular}{cccc}
\hline bidder & $b_{i, t}$ & $a_{i, t}$ & $u_{i, t}$ \\
\hline 1 & 900 & 562.5 & 500 \\
\hline 2 & 600 & 375 & 500 \\
\hline 3 & 800 & 500 & 500 \\
\hline 4 & 100 & 62.5 & $362.5(=62.5-(500-300)+500)$ \\
\hline 5 & 800 & 500 & 500 \\
\hline Total & 3200 & 2000 & -
\end{tabular}

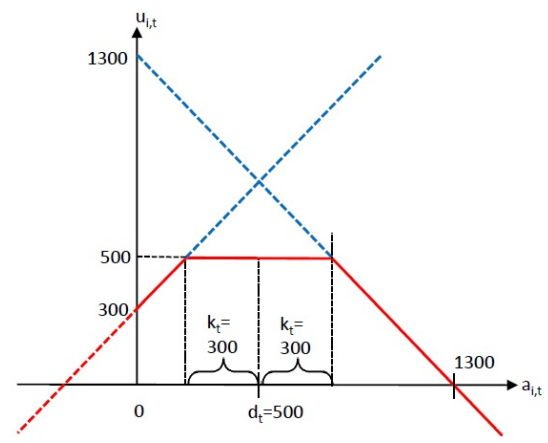

\section{Results}

\subsection{Graphical sketches of the bids and some observations}

Fig.9 and Fig.10 depict the subject bids for Scenarios 1 and 2, respectively. Each line of "team 1" to "team 6 " represents the average bids of five players for the corresponding team. The figures also include the time series of the initial demand $d_{t}$ and the degree of satiation $k_{t}{ }^{8}$.

The (pink) shaded area in each figure represents the range that includes the symmetric Nash equilibrium strategies. First, for $t \leq 7$, the sum of all bidders' demands is smaller than or equal to the total allotment $a=2000$. Therefore, the bid profile where every subject bids its initial demand of $d_{t}$ is the Nash equilibrium strategy. In Fig.9 and Fig.10, this is represented by the pink upward-sloping line ${ }^{9}$. Next, for $8 \leq t \leq 10$, the sum of initial demands (2500) exceeds the total allotment (2000) and no satiation exists in subjects' utility function. This is the situation in which Nautz and Oechssler [14] adopts the Myopic Best-Reply Process (MBR) to describe the overbidding, such that if there is an upper limit in the strategy space, the unique Nash strategy

\footnotetext{
${ }^{8}$ In the Appendix, the median version of Fig.9 and 10 (Fig.12 and 13) and aggregate data among all teams (Fig.14 and 15 ) are also shown.

${ }^{9}$ More precisely, at $t=7$ when initial demand $d_{t}=400$, any symmetric strategy profiles in which all subjects choose the same amount of bids $b$ with $b>400$ are also Nash equilibria. Because our main focus during $t \leq 7$ is to check whether a subject would choose bidding $d_{t}$, all other symmetric Nash strategies are not highlighted.
} 
is to bid the upper limit (Shino [16]), represented by the horizontal pink line at 2000 in Fig.9 and Fig.10. This condition also holds at $t=20,21$ and $t=33,34$ for Scenario 1 and $22 \leq t \leq 24$ and $t=34$ for Scenario 2. Finally, all other periods satisfy the condition that (i) $d_{t}=500$ and (ii) some degrees of satiation exist. In this case, a wide range of bids are supported by the symmetric Nash equilibrium strategy. For example, in both Scenarios 1 and 2, when $t=11, d_{t}=500$, $a_{t}=2000$ and $k_{t}=100$. This implies that bidder $i$ can attain its maximum utility 500 as long as $400 \leq a_{i, t} \leq 600$. Therefore, any symmetric profiles $b_{t}=\left(b_{1, t}, \ldots, b_{n, t}\right)$ satisfying $\sum_{i \in N} b_{i, t} \geq 2000$ yield the maximum utility of 500 given $a_{i, t}=400$, such that $b_{t}$ is a Nash equilibrium.

Figure 9: Average bids of each team in Scenario 1

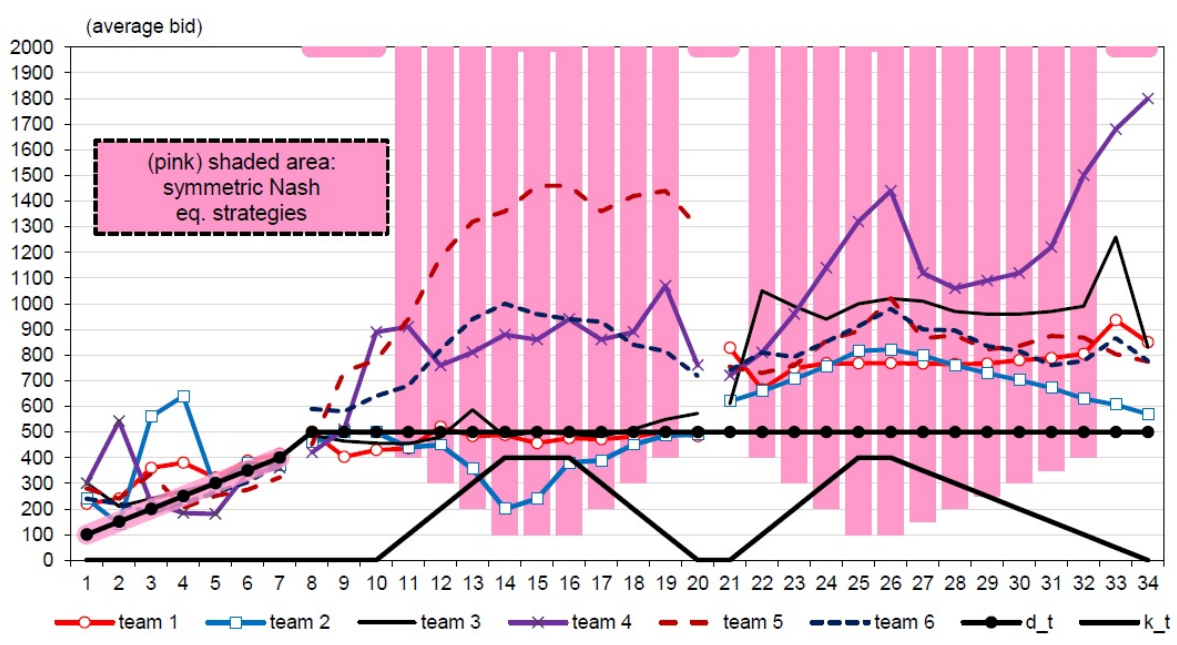

Figure 10: Average bids of each team in Scenario 2

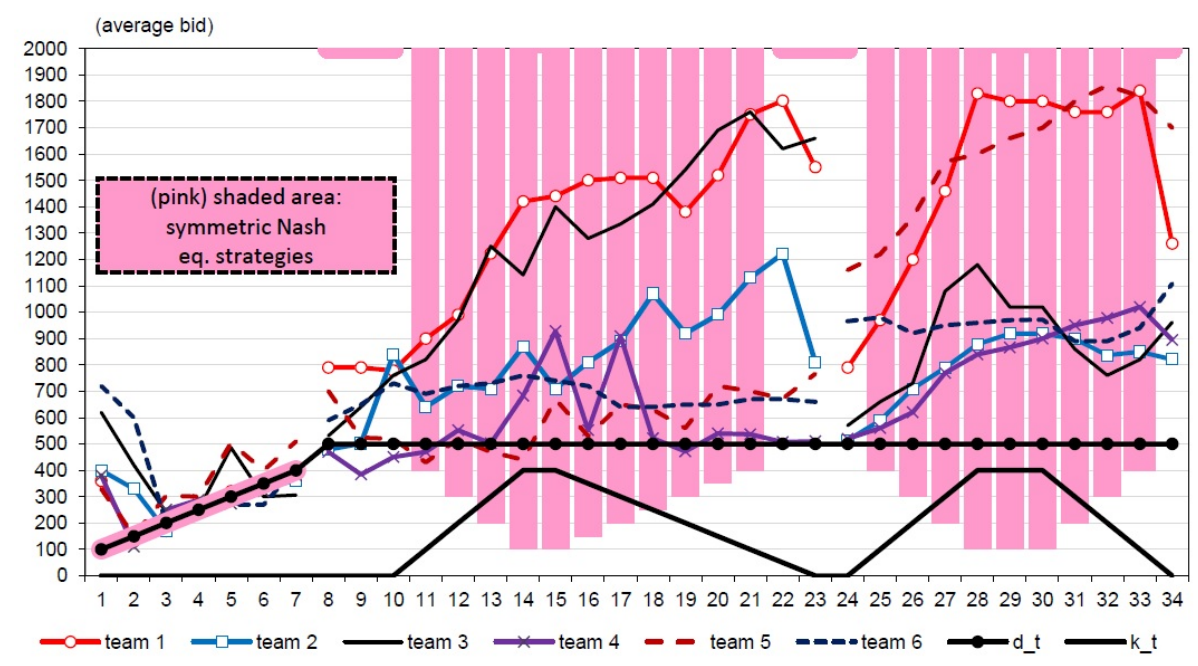

Using Fig.9 and Fig.10, we make the following observations. First, for $1 \leq t \leq 7$, most bidders seem to follow the Nash equilibrium strategy because the lines for teams 1 to 6 are 
very close to and even overlap the pink line. Next, during periods $8 \leq t \leq 10$, the bids in some teams appear to "explode." If so, this seems consistent with the MBR as the existing literature suggests. Finally, for $t \geq 11$ where high initial demand and satiation coexist, a few teams exhibit explosive bids, while others exhibit relatively stable evolutions. In light of these observations, in the following subsections we implement several statistical tests.

\subsection{Hypothesis testing}

\subsubsection{Tests for $1 \leq t \leq 7$ : Nash strategy}

When $1 \leq t \leq 7$, $i^{\prime}$ s unique Nash equilibrium strategy at $t$, denoted by $b_{i, t}^{*}$, is $b_{i, t}^{*}=d_{t}$. We check whether each player follows this strategy. Letting $\bar{b}_{t}$ be the average of all bids at $t$, we confirm the null hypothesis that $\bar{b}_{t}=d_{t}\left(=b_{i, t}^{*}\right)$ for every $t$ with $1 \leq t \leq 7$. The results are shown in Table 1 .

For most periods ( $2 \leq t \leq 7$ for Scenario 1 and $3 \leq t \leq 7$ for Senario 2), the null cannot be rejected with statistical significance at the $5 \%$ level. For $t=1$, the null is rejected for both scenarios (and for $t=2$ for Scenario 2). This might be because subjects' behaviors in the very initial periods of an experiment tend to be subject to "initial effects," i.e., some periods may be needed for subjects to learn the structure of the game and choose an "optimal" strategy using their own reasoning ${ }^{10}$. In sum, the results of the test in Table 1 largely support the hypothesis that each participant follows the unique Nash strategy during $1 \leq t \leq 7$.

Table 1: Hypothesis testing (1) for $1 \leq t \leq 7$

\begin{tabular}{c|ccccccc} 
& \multicolumn{7}{c}{- Scenerio $1-$} \\
period $(t=)$ & 1 & 2 & 3 & 4 & 5 & 6 & 7 \\
\hline demand $\left(d_{t}=\right)$ & 100 & 150 & 200 & 250 & 300 & 350 & 400 \\
\hline \hline Mean bid & 263.4 & 265.7 & 317.7 & 316.9 & 266.2 & 344.4 & 368.8 \\
$(\mathrm{t}$ value $)$ & $\left(4.24^{* * *}\right)$ & $\left(1.71^{*}\right)$ & $(1.60)$ & $(1.05)$ & $(-1.40)$ & $(-0.29)$ & $\left(-1.81^{*}\right)$
\end{tabular}

\begin{tabular}{c|ccccccc} 
& \multicolumn{7}{c}{- Scenerio $2-$} \\
period $(t=)$ & 1 & 2 & 3 & 4 & 5 & 6 & 7 \\
\hline demand $\left(d_{t}=\right)$ & 100 & 150 & 200 & 250 & 300 & 350 & 400 \\
\hline \hline Mean bid & 468.33 & 290.33 & 222.30 & 268.13 & 357.30 & 329.33 & 392.67 \\
$(\mathrm{t}$ value $)$ & $\left(4.18^{* *}\right)$ & $\left(2.34^{* *}\right)$ & $(0.85)$ & $(0.74)$ & $(1.46)$ & $(-0.83)$ & $(-0.27)$
\end{tabular}

(Note) $* * * * *$ and $*$ represent statistical significance at the $1 \%, 5 \%$, and $10 \%$ levels, respectively.

Now, we implement an alternative test to check whether $i$ bids $d_{t}$ for every team and the team aggregate by pooling the data across multiple periods. Specifically, because the level of $b_{i, t}^{*}=d_{t}$ differs for $t$, we take the rate of deviation of $b_{i, t}$ from $b_{i, t}^{*}$. Then, defining $r_{i, t} \equiv\left(b_{i, t}-b_{i, t}^{*}\right) / b_{i, t}^{*}$, we test whether the average of $r_{i, t}$ is zero using a $t$ test. Table 2 provides the results. For the overall

\footnotetext{
${ }^{10}$ While we implemented a practice session before the actual experiment, this result suggests a larger number of periods might be needed.
} 
period $1 \leq t \leq 7$, the null is rejected for all teams and some teams. However, by excluding the initial periods $t=1-2$, the null cannot be rejected, not only for all-team data but also for most of the team-level data. These also suggest the existence of initial effects and we conclude that similar to the previous test, the result supports the view that $i$ follows the unique Nash strategy.

Table 2: Hypothesis testing (2) for $1 \leq t \leq 7$

\begin{tabular}{|c|c|c|c|c|c|c|c|c|}
\hline & & all teams & $\begin{array}{l}\text {-Scene } \\
\text { team1 }\end{array}$ & $\begin{array}{l}\text { o } 1- \\
\text { team2 }\end{array}$ & team3 & team4 & team5 & team6 \\
\hline \multirow[t]{2}{*}{$1 \leq t \leq 7$} & Mean dev. rate & 43.63 & 47.67 & 66.44 & 38.44 & 56.42 & 33.32 & 19.47 \\
\hline & (t value) & $\left(3.87^{* * *}\right)$ & $\left(2.71^{* *}\right)$ & $\left(1.88^{*}\right)$ & (1.43) & (1.43) & (1.51) & (1.28) \\
\hline \multirow[t]{3}{*}{$3 \leq t \leq 7$} & Mean dev. rate & 12.98 & 30.74 & 66.08 & 5.81 & -13.34 & -1.35 & -10.07 \\
\hline & (t value) & $(1.40)$ & $\left(1.72^{*}\right)$ & $(1.50)$ & $(0.65)$ & $(-0.85)$ & $(-0.08)$ & $\left(-2.43^{* *}\right)$ \\
\hline & & all teams & $\begin{array}{l}\text { - Scene } \\
\text { team1 }\end{array}$ & $\begin{array}{l}\text { o } 2- \\
\text { team2 }\end{array}$ & team3 & team 4 & team5 & team6 \\
\hline \multirow[t]{2}{*}{$1 \leq t \leq 7$} & Mean dev. rate & 70.24 & 33.38 & 56.83 & 106.36 & 38.79 & 58.97 & 127.09 \\
\hline & (t value) & $\left(4.27^{* * *}\right)$ & (1.31) & $\left(1.82^{*}\right)$ & $\left(2.12^{* *}\right)$ & $(1.31)$ & $\left(2.13^{* *}\right)$ & $\left(2.07^{* *}\right)$ \\
\hline \multirow[t]{2}{*}{$3 \leq t \leq 7$} & Mean dev. rate & 5.95 & -2.60 & -4.43 & 8.94 & 3.59 & 36.29 & -6.07 \\
\hline & (t value) & (1.29) & $(-0.43)$ & $(-1.07)$ & $(0.46)$ & $(0.41)$ & $\left(2.84^{* * *}\right)$ & $(-0.86)$ \\
\hline
\end{tabular}

(Note) $* * * * *$ and $*$ represent statistical significance at the $1 \%, 5 \%$, and $10 \%$ levels, respectively.

\subsubsection{Tests for $8 \leq t \leq 10$ : MBR}

Our next focus is the subjects' bidding behaviors during the periods $8 \leq t \leq 10$. These periods are characterized by (i) the sum of initial demand $(500 \times 5=2500)$ exceeds the liquidity provision $a=2000$ and (ii) no satiation exists in the subjects' utility function. Theoretical analyses such as Nautz and Oechssler [14] emphasize that in this situation bidders follow the MBR. Let $b_{i, t}^{M B R}$ be the $i^{\prime}$ s best response to the strategy profile of all subjects excluding $i$ at the previous period $b_{-i, t-1} \equiv\left(b_{1, t-1}, \ldots, b_{i-1, t-1}, b_{i+1, t-1}, \ldots, b_{n, t-1}\right)$. Note that we can obtain $b_{-i, t-1}$ from the experiment thus compute $b_{i, t}^{M B R}$. Then, we check whether each player follows $b_{i, t}^{M B R}$. Similar to the previous case of $1 \leq t \leq 7$, we implement two different types of statistical tests. First, we check the validity of the null at every period. In particular, noting that $b_{i, t}^{M B R}$ differs for $i$ depending on $b_{-i, t-1}$, we take the rate of deviation of the actual $b_{i, t}$ from the computed $b_{i, t}^{M B R}$, denoted by $\beta_{i, t} \equiv\left(b_{i, t}-b_{i, t}^{M B R}\right) / b_{i, t}^{M B R}$, and check if $\bar{\beta}_{i, t}$, the average of $\beta_{i, t}$ over all subjects for a given $t$, is zero. Table 3 details the results.

Next, we apply an alternative test by pooling the data for multiple periods. For each team or aggregate of all teams, we check if $\bar{\beta}_{i, t}$, an average of $\beta_{i, t}$ over subjects in an associated team(s) and over an associated period(s), is zero. Table 4 provides the results.

The result for both tests seems somewhat mixed. For example, while some team-level data demonstrate consistency with the null that subjects play $b_{i, t}^{M B R}$, other team-level data, as well as the all-team data, reject the null. Similar to the previous case, however, if we exclude the first 
two periods $(t=8,9)$, the null cannot be rejected for most cases in both tests. In this regard, the evidence in Table 3 and 4 shows consistency with our view that $i$ follows $b_{i, t}^{M B R}$. However, we note that we can draw only weak conclusions from these results and a larger number of periods would be needed to obtain clearer evidence. We identify this as an issue for further research.

Table 3: Hypothesis testing (3) for $8 \leq t \leq 10$

\begin{tabular}{c|ccc} 
period $(t=)$ & - Scenerio $1-$ & & \\
Mean deviation from $\beta_{i, t}^{M B R}\left(=\bar{\beta}_{i, t}\right)$ & 0.00 & -0.15 & -0.13 \\
$(\mathrm{t}$ value $)$ & $(-0.01)$ & $\left(-2.39^{* *}\right)$ & $\left(-1.76^{*}\right)$ \\
period $(t=)$ & - Scenerio $2-$ & & \\
\hline Mean deviation from $\beta_{i, t}^{M B R}\left(=\bar{\beta}_{i, t}\right)$ & 0.15 & -0.23 & -0.10 \\
(t value) & $(1.09)$ & $\left(-2.97^{* * *}\right)$ & $(-1.20)$
\end{tabular}

(Note) $* * * * *$ and $*$ represent statistical significance at the $1 \%, 5 \%$, and $10 \%$ levels, respectively.

Table 4: Hypothesis testing (4) for $8 \leq t \leq 10$

\begin{tabular}{c|c|ccccccc} 
& & \multicolumn{7}{c}{- Scenerio 1 - } \\
& & all teams & team1 & team2 & team3 & team4 & team5 & team6 \\
\hline $8 \leq t$ & Mean dev. & -9.36 & -22.48 & -16.66 & -16.00 & 2.57 & 4.54 & -8.11 \\
$\leq 10$ & rate ( $\mathrm{t}$ val.) & $\left(-2.38^{* *}\right)$ & $\left(-3.02^{* * *}\right)$ & $\left(-3.51^{* * *}\right)$ & $(-1.35)$ & $(0.16)$ & $(0.35)$ & $(-0.77)$ \\
\hline $\mathrm{t}=10$ & Mean dev. & -12.83 & -18.52 & -25.13 & -24.02 & 27.54 & -19.92 & -16.95 \\
& rate (t val.) & $\left(-1.79^{*}\right)$ & $\left(-2.00^{*}\right)$ & $\left(-5.64^{* * *}\right)$ & $\left(-1.96^{*}\right)$ & $(0.87)$ & $(-1.57)$ & $\left(-2.76^{* * *}\right)$
\end{tabular}

\begin{tabular}{c|c|ccccccc} 
& & \multicolumn{7}{c}{- Scenerio 2 -} \\
& & all teams & team1 & team2 & team3 & team4 & team5 & team6 \\
\hline $8 \leq t$ & Mean dev. & -6.02 & 0.07 & 0.38 & 7.68 & -19.01 & -17.50 & -7.76 \\
$\leq 10$ & rate ( $\mathrm{t}$ val.) & $(-1.01)$ & $(0.00)$ & $(0.02)$ & $(0.45)$ & $\left(-2.84^{* * *}\right)$ & $(-0.78)$ & $(-1.07)$ \\
\hline $\mathrm{t}=10$ & Mean dev. & -9.69 & -21.97 & 21.35 & -7.97 & -11.46 & -22.93 & -15.17 \\
& rate ( $\mathrm{t}$ val.) & $(-1.22)$ & $(-1.36)$ & $(0.66)$ & $(-0.45)$ & $(-1.44)$ & $(-1.42)$ & $\left(-1.92^{*}\right)$
\end{tabular}

(Note) $* * * * *$ and $*$ represent statistical significance at the $1 \%, 5 \%$, and $10 \%$ levels, respectively.

\subsubsection{Tests for $t \geq 11$ : Role of satiation}

Finally, we focus on those periods where $t \geq 11$. During these periods, the subjects' utility functions are locally satiated, such that a wide range of bids are included in the set of symmetric Nash strategies. Recall that such a situation corresponds to an accommodative financial environment and where the level of interest rates applied to the complementary deposit facility is strictly positive. In this situation, the theoretical analysis in Shino [16] argues that the locally satiated utility function should prevent the bid-to-cover ratio from exploding. Indeed, as we observed in Fig.9 and Fig.10, although a few teams exhibit explosive bids, most teams exhibit 
relatively stable bids. In this regard, it should be mentioned that in an informal interview with some of the subjects following the experiment on their views on biddings, some responded that "I aimed to obtain $a_{i, t}=500$ even when $k_{t}$ is large." This suggests that some subjects behaved in such a way as to trigger overbidding.

In sum, we would like to confirm whether satiated objective functions have some power to avoid overbidding. If this is true, letting $\tilde{b}_{i, t}^{M B R}$ be an $i^{\prime}$ s MBR strategy at $t$ when $k_{t}=0$ (no satiation), the following must be rejected: $i$ plays $\tilde{b}_{i, t}^{M B R}$. Because $\tilde{b}_{i, t}^{M B R}$ can be computed by $b_{-i, t-1}$, this statement is obviously statistically testable as in the previous case. Letting $\tilde{\beta}_{i, t} \equiv\left(b_{i, t}-\tilde{b}_{i, t}^{M B R}\right) / \tilde{b}_{i, t}^{M B R}$, we check $\tilde{\tilde{\beta}}_{i, t}$ (average of $\tilde{\beta}_{i, t}$ ) is zero. Table 5 and Table 6 detail the results ${ }^{11}$. Because we are particularly interested in whether the actual bid $b_{i, t}$ is significantly less than $\tilde{b}_{i, t}^{M B R}$, we use one-sided tests for computing the significance levels.

Table 5: Hypothesis testing (5) for $t \geq 11$

\begin{tabular}{|c|c|c|c|c|c|c|c|}
\hline \multicolumn{8}{|c|}{ - Scenerio 1 - } \\
\hline$t=$ & 11 & 12 & 13 & 14 & 15 & 16 & 17 \\
\hline$\overline{\tilde{\beta}}_{i, t}$ & -0.22 & -0.16 & -0.18 & -0.27 & -0.17 & -0.13 & -0.24 \\
\hline (t val.) & $\left(-3.48^{* * *}\right)$ & $\left(-2.54^{* * *}\right)$ & $\left(-2.29^{* *}\right)$ & $\left(-3.24^{* * *}\right)$ & $\left(-1.84^{* *}\right)$ & $(-1.36)$ & $\left(-3.65^{* * *}\right)$ \\
\hline$t=$ & 18 & 19 & 22 & 23 & 24 & 25 & 26 \\
\hline$\overline{\tilde{\beta}}_{i, t}$ & -0.19 & -0.18 & -0.15 & -0.19 & -0.18 & -0.17 & -0.18 \\
\hline (t val.) & $\left(-2.83^{* * *}\right)$ & $\left(-3.22^{* * *}\right)$ & $\left(-1.79^{* *}\right)$ & $\left(-3.66^{* * *}\right)$ & $\left(-3.25^{* * *}\right)$ & $\left(-2.73^{* * *}\right)$ & $\left(-2.57^{* * *}\right)$ \\
\hline$t=$ & 27 & 28 & 29 & 30 & 31 & 32 & 33 \\
\hline$\overline{\tilde{\beta}}_{i, t}$ & -0.29 & -0.24 & -0.25 & -0.23 & -0.23 & -0.21 & -0.17 \\
\hline (t val.) & $\left(-4.83^{* * *}\right)$ & $\left(-4.70^{* * *}\right)$ & $\left(-4.62^{* * *}\right)$ & $\left(-4.73^{* * *}\right)$ & $\left(-5.04^{* * *}\right)$ & $\left(-4.63^{* * *}\right)$ & $\left(-4.12^{* * *}\right)$ \\
\hline \multicolumn{8}{|c|}{ - Scenerio 2 - } \\
\hline$t=$ & 11 & 12 & 13 & 14 & 15 & 16 & 17 \\
\hline$\overline{\tilde{\beta}}_{i, t}$ & -0.26 & -0.12 & -0.19 & -0.14 & -0.11 & -0.30 & -0.13 \\
\hline (t val.) & $\left(-4.41^{* * *}\right)$ & $\left(-1.98^{* *}\right)$ & $\left(-2.87^{* * *}\right)$ & $\left(-1.70^{* *}\right)$ & $(-1.29)$ & $\left(-5.10^{* * *}\right)$ & $\left(-1.80^{* *}\right)$ \\
\hline$t=$ & 18 & 19 & 20 & 21 & 22 & 25 & 26 \\
\hline$\overline{\tilde{\beta}}_{i, t}$ & -0.26 & -0.28 & -0.15 & -0.20 & -0.25 & -0.15 & -0.15 \\
\hline (t val.) & $\left(-5.09^{* * *}\right)$ & $\left(-6.83^{* * *}\right)$ & $\left(-2.90^{* * *}\right)$ & $\left(-5.33^{* * *}\right)$ & $\left(-5.71^{* * *}\right)$ & $\left(-3.17^{* * *}\right)$ & $\left(-3.62^{* * *}\right)$ \\
\hline$t=$ & 27 & 28 & 29 & 30 & 31 & 32 & 33 \\
\hline$\overline{\overline{\tilde{\beta}}_{i, t}}$ & -0.09 & -0.16 & -0.24 & -0.23 & -0.26 & -0.25 & -0.21 \\
\hline (t val.) & $\left(-1.76^{* *}\right)$ & $\left(-3.29^{* * *}\right)$ & $\left(-6.82^{* * *}\right)$ & $\left(-6.48^{* * *}\right)$ & $\left(-6.96^{* * *}\right)$ & $\left(-5.93^{* * *}\right)$ & $\left(-5.63^{* * *}\right)$ \\
\hline
\end{tabular}

(Note) $* * * * *$ and $*$ represent statistical (one-sided test) significance at the $1 \%, 5 \%$, and $10 \%$ levels, respectively.

The results in Table 5 indicate that the null that bidders still follow MBR is rejected for 19 of the 21 periods in Scenario 1 and 20 of the 21 periods in Scenario 2. Similarly, the results in

\footnotetext{
${ }^{11}$ More precisely, we exclude $t=20,21,34$ for Scenario 1 and $t=23,24,34$ for Scenario 2 from the test periods because in these no satiation exists $\left(k_{t}=0\right)$.
} 
Table 6 show that all-team-level data reject the null during the associated periods and almost all of the team-level data reject the null at a significance level of $1 \%$. These results are clearly different from those for the previous case of $8 \leq t \leq 10$. Therefore, we conclude that locally satiated objective functions - as proxies for an accommodative financial environment and strictly positive interest rates applied to the complementary deposit facility- contribute to preventing the participants' bids from exploding.

Table 6: Hypothesis testing (6) for $t \geq 11$

\begin{tabular}{|c|c|c|c|c|c|c|c|c|}
\hline & & all teams & team1 & $\begin{array}{l}\text { - Scenerio } 1- \\
\text { team2 }\end{array}$ & team 3 & team4 & team5 & team6 \\
\hline $\begin{array}{r}11 \leq t \\
\leq 19\end{array}$ & $\begin{array}{l}\text { Mean dev. } \\
\text { rate (t val.) }\end{array}$ & $\begin{array}{c}-19.44 \\
\left(-7.84^{* * *}\right)\end{array}$ & $\begin{array}{c}-22.84 \\
\left(-8.60^{* * *}\right)\end{array}$ & $\begin{array}{c}-18.89 \\
\left(-2.43^{* * *}\right)\end{array}$ & $\begin{array}{c}-21.03 \\
\left(-4.51^{* * *}\right)\end{array}$ & $\begin{array}{c}-17.07 \\
\left(-1.97^{* *}\right)\end{array}$ & $\begin{array}{c}-15.75 \\
\left(-2.53^{* * *}\right)\end{array}$ & $\begin{array}{c}-21.08 \\
\left(-5.00^{* * *}\right)\end{array}$ \\
\hline $\begin{aligned} & 22 \leq t \\
& \leq 33\end{aligned}$ & $\begin{array}{l}\text { Mean dev. } \\
\text { rate ( } t \text { val.) }\end{array}$ & $\begin{array}{c}-20.74 \\
\left(-12.77^{* * *}\right)\end{array}$ & $\begin{array}{c}-22.21 \\
\left(-5.80^{* * *}\right)\end{array}$ & $\begin{array}{c}-23.90 \\
\left(-9.15^{* * *}\right)\end{array}$ & $\begin{array}{c}-15.53 \\
\left(-2.56^{* * *}\right)\end{array}$ & $\begin{array}{c}-18.26 \\
\left(-6.52^{* * *}\right)\end{array}$ & $\begin{array}{c}-21.25 \\
\left(-4.36^{* * *}\right)\end{array}$ & $\begin{array}{c}-23.31 \\
\left(-11.23^{* * *}\right)\end{array}$ \\
\hline
\end{tabular}

\begin{tabular}{c|c|ccccccc} 
& & \multicolumn{7}{c}{- Scenerio 2 -} \\
all teams & team1 & team2 & team3 & team4 & team5 & team6 \\
\hline $11 \leq t$ & Mean dev. & -19.93 & -17.53 & -19.77 & -17.00 & -20.35 & -20.43 & -24.48 \\
$\leq 22$ & rate (t val.) & $\left(-11.31^{* * *}\right)$ & $\left(-4.81^{* * *}\right)$ & $\left(-4.44^{* * *}\right)$ & $\left(-3.53^{* * *}\right)$ & $\left(-3.92^{* * *}\right)$ & $\left(-4.42^{* * *}\right)$ & $\left(-9.53^{* * *}\right)$ \\
\hline $25 \leq t$ & Mean dev. & -19.54 & -16.54 & -19.44 & -19.35 & -18.46 & -19.75 & -23.70 \\
$\leq 33$ & rate (t val.) & $\left(-13.63^{* * *}\right)$ & $\left(-5.71^{* * *}\right)$ & $\left(-5.94^{* * *}\right)$ & $\left(-4.05^{* * *}\right)$ & $\left(-7.01^{* * *}\right)$ & $\left(-5.60^{* * *}\right)$ & $\left(-6.80^{* * *}\right)$
\end{tabular}

(Note) $* * * * *$ and $*$ represent statistical (one-sided test) significance at the $1 \%, 5 \%$, and $10 \%$ levels, respectively.

\subsection{Bid functions}

To this point, we implemented statistical tests to check whether the actual bidding patterns in the experiments are consistent with those suggested by theoretical analyses such as Nautz and Oechssler [14] and Shino [16]. Our other interest lies in examining the effects of changes in the degree of satiation in subjects' utility function on their bidding behavior. To consider this, in this subsection we identify subjects' bid functions. Based on the estimated bid functions, the following subsection implements a simple calibration.

Before constructing specific functional forms, we first define the following three dummy variables:

$$
\begin{gathered}
\text { dum } 1_{i, t}=\left\{\begin{array}{cc}
1 & \text { if } u_{i, t-1}<500 \text { and } a_{i, t-1}>500 \\
0 & \text { otherwise }
\end{array}\right. \\
\text { dum } 2_{i, t}=\left\{\begin{array}{lc}
1 & \text { if } u_{i, t-1}<500 \text { and } a_{i, t-1}<500 \\
0 & \text { otherwise }
\end{array}\right. \\
\text { dum } 3_{i, t}=\left\{\begin{array}{cc}
1 & \text { if } u_{i, t-1}=500 \\
0 & \text { otherwise }
\end{array}\right.
\end{gathered}
$$

First, suppose that bidder $i$ receives the maximum level of utility of 500 at $t-1$. Then $d u m 3_{i, t}=1$ and $d u m 1_{i, t}=d u m 2_{i, t}=0$. Next, suppose that $i$ fails to obtain the maximum level 
of utility at $t-1$. This occurs when one of the following two cases arises. The first is that $i$ 's actual allotment $a_{i, t-1}$ is too much, more specifically, $a_{i, t-1}>d_{t-1}+k_{t-1}$. In this case, dum $1_{i, t}=1$ and $d u m 2_{i, t}=d u m 3_{i, t}=0$. The second is that $i$ 's actual allotment is too small, $a_{i, t-1}<d_{t-1}-k_{t-1}$, which results in $d u m 2_{i, t}=1$ while $d u m 1_{i, t}=d u m 3_{i, t}=0$. By using these dummy variables, we construct and estimate the following bid functions: (3), (4) and (5).

$$
\begin{gathered}
b_{i, t}=c+\alpha b_{i, t-1}+\beta_{1} d u m 1_{i, t} \cdot\left(500-u_{i, t-1}\right)+\beta_{2} d u m 2_{i, t} \cdot\left(500-u_{i, t-1}\right) \\
b_{i, t}=c+\alpha b_{i, t-1}+\gamma d u m 3_{i, t} \cdot b_{i, t-1}+\beta_{1} d u m 1_{i, t} \cdot\left(500-u_{i, t-1}\right)+\beta_{2} d u m 2_{i, t} \cdot\left(500-u_{i, t-1}\right) \\
b_{i, t}=\alpha b_{i, t-1}+\gamma d u m 3_{i, t} \cdot b_{i, t-1}+\beta_{1} d u m 1_{i, t} \cdot\left(500-u_{i, t-1}\right)+\beta_{2} d u m 2_{i, t} \cdot\left(500-u_{i, t-1}\right)
\end{gathered}
$$

The underlying idea behind all bid functions is essentially identical, so, we first select the bid function (3) to explain this. First, note that there is the "adaptive term" $\alpha b_{i, t-1}$. If subject $i$ 's bid at $t$ is influenced by its own previous period, $\alpha$ takes a positive value and is statistically significant. Furthermore, function (3) has two other terms including $d u m 1_{i, t}$ and $d u m 2_{i, t}$. Regarding these terms, first suppose that $u_{i, t-1}<500$ and $a_{i, t-1}>500$, that is, $i$ 's allotment was too much to obtain the maximum utility. In this case, $d u m 1_{i, t}=1, d u m 2_{i, t}=0$ thus equation (3) turns to $b_{i, t}=c+\alpha b_{i, t-1}+\beta_{1}\left(500-u_{i, t-1}\right)$. Here, our conjecture is $\beta_{1}<0$ for the following reasoning. At $t-1, i$ fails to attain its maximum utility because $i$ took too much. By learning from this experience, at $t i$ is expected to bid less so that actual allotment $a_{i, t}$ lies in the range of $\left[d_{t}-k_{t}, d_{t}+k_{t}\right]$. This condition corresponds to $\beta_{1}\left(500-u_{i, t-1}\right)<0$. Because $\left(500-u_{i, t-1}\right)>0$ we conjecture that $\beta_{1}<0$. Conversely, suppose next that $i$ fails to get the maximum utility because $i$ 's allotment is too small, that is, $u_{i, t-1}<500$ and $a_{i, t-1}<500$. In this case, dum $1_{i, t}=0$, dum $2_{i, t}=1$ thus (3) becomes $b_{i, t}=c+\alpha b_{i, t-1}+\beta_{2} \cdot\left(500-u_{i, t-1}\right)$. Given $i$ is expected to bid more than the previous period through the learning effects, $\beta_{2}>0$ is expected.

The bid functions of (4) and (5) also include $d u m 1_{i, t}$ and $d u m 2_{i, t}$ drawing on the same premise. (4) is formed by adding $\left[\gamma d u m 3_{i, t} \cdot b_{i, t-1}\right]$ to (3). This is based on the assumption that the sensitivity of bid at $t$ to the previous bid $b_{i, t-1}$, in other words, how adaptive $i$ 's bidding is, depends on whether $i$ obtained the maximum utility at $t-1$. If $i$ received the maximum, then $d u m 3_{i, t}=1$ so the sensitivity is expressed as $(\alpha+\gamma) b_{i, t-1}$. Otherwise, it is $\alpha b_{i, t-1}$. Equation (5) is used to check whether $i$ 's bidding behavior can be expressed as a "completely adaptive" function in some cases. Specifically, suppose $u_{i, t-1}=500$. In such a case, a reasonable conjecture is that $i$ continues to make the same bid amount. Because the constant term is dropped in (5), this condition can be simply expressed as $\alpha+\gamma=1$. If this condition holds, then (5) becomes $b_{i, t}=(\alpha+\gamma) b_{i, t-1}=b_{i, t-1}$.

We provide the following two remarks. First, the construction of the bid functions (3) to (5) is based on the assumption that a subject makes a decision on the bid depending on the following three cases at the previous period: (A) succeeds in obtaining the maximum utility, (B) fails to obtain the maximum utility because of a shortage, and $(C)$ fails to obtain the maximum utility because of abundance. Which case of (A) to (C) is likely to occur crucially depends on the degree of satiation $k_{t}$. For example, (A) is more likely to occur as $k_{t}$ increases. In this sense, 
the subjects' bidding behaviors expressed as functional forms of (3) to (5) are influenced by the degree of satiation. Second, we estimate (3) and (4) using fixed-effects panel models and (5) by pooling ordinary least squares (OLS) models. For the fixed-effects regressions, Hausman tests reject the null hypothesis of no correlation between regressors and effects for all cases and thus support their use. Alternatively, we employ pooling OLS for (5) because our interest lies in bidding, which can be expressed in the simple form of $b_{i, t}=b_{i, t-1}$. If we add individual effects $F_{i}$ (either fixed or random) to (5), then (5) cannot take the form of $b_{i, t}=b_{i, t-1}$, thus we cannot check if the bidding behavior becomes "completely adaptive." Therefore, we estimate (5) by pooling OLS ${ }^{12}$.

Table 7: Identification of bid functions

\begin{tabular}{c|c|c|c|c|c} 
& \multicolumn{7}{|c|}{ Scenerio $1-$} \\
& const & $\alpha$ & $\beta_{1}$ & $\beta_{2}$ & $\gamma$ \\
\hline \multirow{3}{*}{ equation (3) } & $\begin{array}{c}205.92^{* * *} \\
(7.73)\end{array}$ & $\begin{array}{c}0.75^{* * *} \\
(25.69)\end{array}$ & $\begin{array}{c}-3.52^{* * *} \\
(-14.05)\end{array}$ & $\begin{array}{c}0.80^{* * *} \\
(5.79)\end{array}$ & - \\
& $\begin{array}{c}203.85^{* * *} \\
(7.64)\end{array}$ & $0.72^{* * *}$ & $-3.34^{* * *}$ & $0.89^{* * *}$ & 0.04 \\
equation (4) & $(19.19)$ & $(-11.30)$ & $(5.62)$ & $(1.19)$ \\
& - & $0.94^{* * *}$ & $-3.54^{* * *}$ & $1.25^{* * *}$ & $0.05^{* *}$ \\
equation (5) & - & $(33.48)$ & $(-11.76)$ & $(8.57)$ & $(1.79)$
\end{tabular}

\begin{tabular}{|c|c|c|c|c|c|}
\hline & \multicolumn{4}{|c|}{ - Scenerio 2 - } & \multirow[b]{2}{*}{$\gamma$} \\
\hline & const & $\alpha$ & $\beta_{1}$ & $\beta_{2}$ & \\
\hline equation (3) & $\begin{array}{c}354.56^{* * *} \\
(10.37)\end{array}$ & $\begin{array}{l}0.68^{* * *} \\
(21.55)\end{array}$ & $\begin{array}{c}-2.677^{* * *} \\
(-7.00)\end{array}$ & $\begin{array}{l}0.04 \\
(0.24)\end{array}$ & - \\
\hline equation (4) & $\begin{array}{c}364.85^{* * *} \\
(10.73)\end{array}$ & $\begin{array}{l}0.56^{* * *} \\
(12.47)\end{array}$ & $\begin{array}{l}-1.92^{* * *} \\
(-4.46)\end{array}$ & $\begin{array}{l}0.33^{*} \\
(1.64)\end{array}$ & $\begin{array}{l}0.12^{* * * *} \\
(3.65)\end{array}$ \\
\hline equation (5) & - & $\begin{array}{l}0.91^{* * *} \\
(27.59)\end{array}$ & $\begin{array}{l}-2.31^{* * *} \\
(-5.12)\end{array}$ & $\begin{array}{c}1.14^{* * * *} \\
(6.14)\end{array}$ & $\begin{array}{l}0.10^{* * * *} \\
(2.78)\end{array}$ \\
\hline
\end{tabular}

Notes: 1 . Confidence levels are $* * *$ for $p<0.01, * *$ for $p<0.05$, and $*$ for $p<0.10$.

2. $\mathrm{t}$ values in parentheses.

For estimation, we use the data for $t \geq 11$ because our primary focus is the effects of satiation on bidding patterns. Table 7 details the estimated coefficients and associated $t$ values for Scenario 1 and Scenario 2. Consistent with our argument above, the results of the estimations are reasonable. First, for both scenarios, $\beta_{1}$ is negative, $\beta_{2}$ is positive and statistically significant in most cases. Second, as for the $\alpha$, all models suggest positive estimated parameters and all of them are statistically significant, which implies that the subjects more or less tend to preserve their "adaptive" stance. Furthermore, in equation (5), the sum of the estimated coefficients for $\alpha$ and $\gamma$ is almost 1 for both scenarios. This suggests that subjects have a strong tendency to continue to bid the same amount as the previous period as long as they realize the maximum level of utility, that is, the actual allotment is within the range of $\left[d_{t}-k_{t}, d_{t}+k_{t}\right]$. Note that this

\footnotetext{
${ }^{12}$ As a topic for further research, finding an appropriate variable to act as an instrument would statistically improve the estimation results.
} 
does not require the actual allotment to locate at the "central" point of $d_{t}$. We regard this as evidence that the degree of satiation $k_{t}$ affects subjects' bidding patterns.

In sum, our identified functional forms and estimation results imply a subject's learning process based on its own past experience in adjusting the amount of bids. Furthermore, it also demonstrates the role of the degree of satiation $k_{t}$ in stabilizing $b_{i, t}$ through making the range of actual allotments where the subjects can attain maximum utility wider and through enhancing subjects' incentives to continue bidding the same amount over successive periods. In the next subsection, we further examine the effects of changes in the degree of satiation on bidding patterns by a simple calibration using the estimated parameters in the bid function (5).

\subsection{Calibration}

As shown in the previous subsection, the satiated objective function has the effect of stabilizing the participants' bidding behavior. However, the results also entail the possibility that a change in the degree of satiation could destabilize bidding patterns in this type of auction, even when a certain degree of satiation is preserved. To examine this issue, we select equation (5) and consider the following specific functional form based on the estimated parameter derived for Scenario 1:

$$
b_{i, t}=0.94 b_{i, t-1}+0.05 d u m 3_{i, t} \cdot b_{i, t-1}-3.5 d u m 1_{i, t} \cdot\left(500-u_{i, t-1}\right)+1.2 d u m 2_{i, t} \cdot\left(500-u_{i, t-1}\right)
$$

We check the evolution of bids for each different degree of satiation $k_{t}$ under a specific amount of funds provided and the initial demands of participants. Specifically, at the initial period $t$, suppose that $a=2000, d_{t}=500, k_{t}=200$, and $\left(b_{i, t}=500\right)(\forall i \in N)$. That is, at the initial period $t$, the sum of all bids exceeds the amount of funds provided, but all participants obtain the maximum utility of 500 because the actual allotment $a_{i, t}=400$ lies in the range of $\left[d_{t}-k_{t}, d_{t}+k_{t}\right]=$ $[300,700]$. Furthermore, we assume that, at $t+1, k_{t+1}$ decreases and remains at this level until the end of the game. Fig.11 plots the evolution of average bids for the different $k_{t+1}$.

The chart illustrates that $b_{i, t}$ tends to explode even when $k>0$, specifically, $0<k<60$. Recalling that the existence of positive satiation corresponds to an accommodative financial environment, we consider the evolution of bids for each of the cases. First, when $k_{t+1}=100$, $u_{i, t+1}=500$ is realized. Therefore, $d u m 1_{i, t+2}=d u m 2_{i, t+2}=0$ and $d u m 3_{i, t+2}=1$, thus, the bidding function (6) simply becomes $b_{i, t}=0.99 b_{i, t-1}$. This produces a linear declining trend of $b_{i, t}$ and this continues as long as $b_{i, t} \geq 400$ holds $^{13}$. Once $b_{i, t}<400$ holds, however, then equation (6) changes to $b_{i, t}=0.94 b_{i, t-1}+1.2\left(500-u_{i, t-1}\right)$ because $a_{i, t}<400$ and $u_{i, t}<500$, that is, $i^{\prime}$ s allotment is too small. Once this condition holds, $b_{i, t}$ could increase depending on the effect of decreasing bids by $0.94 b_{i, t-1}$ and the effect of increasing bids by $1.2\left(500-u_{i, t-1}\right)$ (indeed $b_{i, t}$ increases to 382 at $t=26$ from 376 at $t=25$, after showing a moderate decreasing trend). However, the bids exhibit a stable evolution under a relatively large $k_{t}=100$ overall. The same argument holds

\footnotetext{
${ }^{13}$ If the estimated parameter regarding $b_{i, t}$ is 0.95 instead of 0.94 , then $b_{i, t}=500$ continues permanently given (6) becomes $b_{i, t}=b_{i, t-1}$.
} 
for $k=80$.

Conversely, when $k \leq 60, b_{i, t}$ follows an increasing trend. For example, select the case when $k_{t+1}=40$. Then, $\left[d_{t+1}-k_{t+1}, d_{t+1}+k_{t+1}\right]=[460,540]$ thus $a_{i, t+1}=400$ locates out of this range, which results in $d u m 2_{i, t+2}=1$ and $d u m 1_{i, t+2}=d u m 3_{i, t+2}=0$. Therefore, the bidding function (6) becomes $b_{i, t}=0.94 b_{i, t-1}+1.2\left(500-u_{i, t-1}\right)$ from $t+2$. At $t+2, b_{i, t+2}=0.94 \cdot 495\left(=b_{i, t+1}\right)+$ $1.2(500-440)=537.3$. In this case, $b_{i, t+2}>b_{i, t+1}$ because the effect of the term $1.2\left(500-u_{i, t-1}\right)$ to increase the amount of bids is dominant. Given that this mechanism works, the bids follow an increasing trend and the same argument holds for $k=40,20$, and 0 . This result implies that a vulnerability to overbidding in fixed-rate operations can materialize, even when subjects' objective functions are locally satiated.

While we identify increasing trends of bids even under strictly positive $k_{t}$, the speed appears to decelerate. This is because the term $0.94 b_{i, t-1}$ in the bid function (6) exerts downward pressure on the increase in bids. However, note that in this calibration we only include a one-shot change in the degree of satiation $k_{t+1}$. During the process of "normalization" in the actual conduct of monetary policy, $k_{t}$ is naturally expected to decrease gradually and continuously over a certain number of periods. In such a scenario, the speed of increase might not be able to decelerate, and we could then not exclude the risk of a bid explosion judging from these observations.

Figure 11: Calibration: Average bids for different $k$

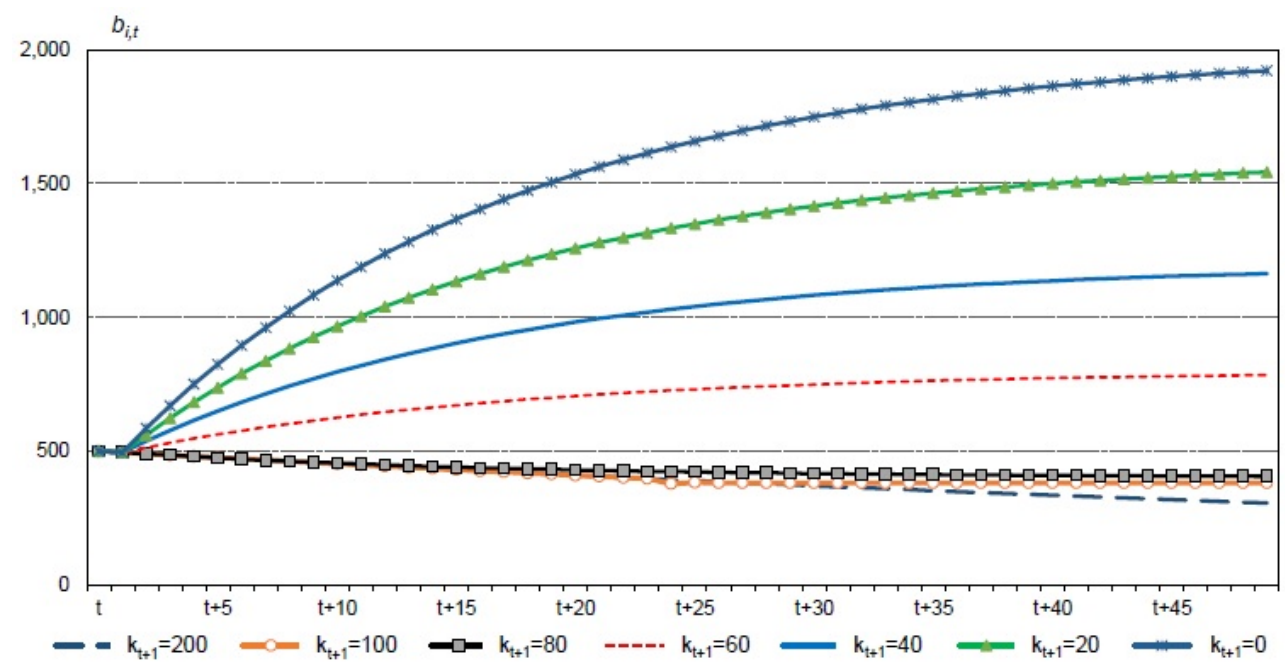

Notes: We assume that (i) each bidder follows the bid function expressed as (6) and (ii) at $t$ (initial period), $d_{t}=500$, $k_{t}=200$, and $\left(b_{i, t}=500\right)(\forall i \in N)$. Each line represents the evolution of average bids when $k_{t+1}$ decreases to the associated number from 200 to 0 at $t+1$ and remains at this level by $t=50$.

\section{Conclusion}

In this paper, we implemented an experiment using fixed-rate funds-supplying operations. The results showed that: (1) when participants' initial demands are sufficiently small, they simply play the unique Nash equilibrium strategy of bidding their true demand, (2) as the demand 
becomes large and no satiation exists in their objective functions, participants tend to overbid. However, (3) even as the demands become large, the explosion of bids does not occur if the objective functions are sufficiently satiated. Furthermore, (4) we estimate subjects' bid functions in which the bids are influenced by the degree of satiation through their utility functions and (5) a simple calibration based on the estimated bid functions points out the vulnerability of fixed-rate operations to overbidding even when satiation is preserved.

We conclude the analysis by identifying several questions for further research. First, while the calibration implemented in this paper reveals the effects of change in the degree of satiation on subjects' bidding patterns, there is as yet no direct evidence of how the differences in the speed of easing or normalization affects their bids. In this regard, a larger number of periods may be needed to derive a significant difference between Scenarios 1 and 2. Furthermore, regarding the appropriate number of periods, if some periods were to be added to the phases of (i) "small initial demands environment" ( $t$ with $1 \leq t \leq 7$ ) and (ii) "large initial demands without satiation environment" ( $t$ with $8 \leq t \leq 10$ ), then "initial effects" referred in Subsection 4.2 would wane and it might give rise to more evident findings. Lastly, an examination of the effects of negative interest rates, as introduced by both the ECB and the BOJ in recent years, on bidding patterns in fixed-rate operations could be an intriguing topic ${ }^{14}$.

\section{Appendix: some complementary charts}

Figure 12: Median bids of each team in Scenario 1

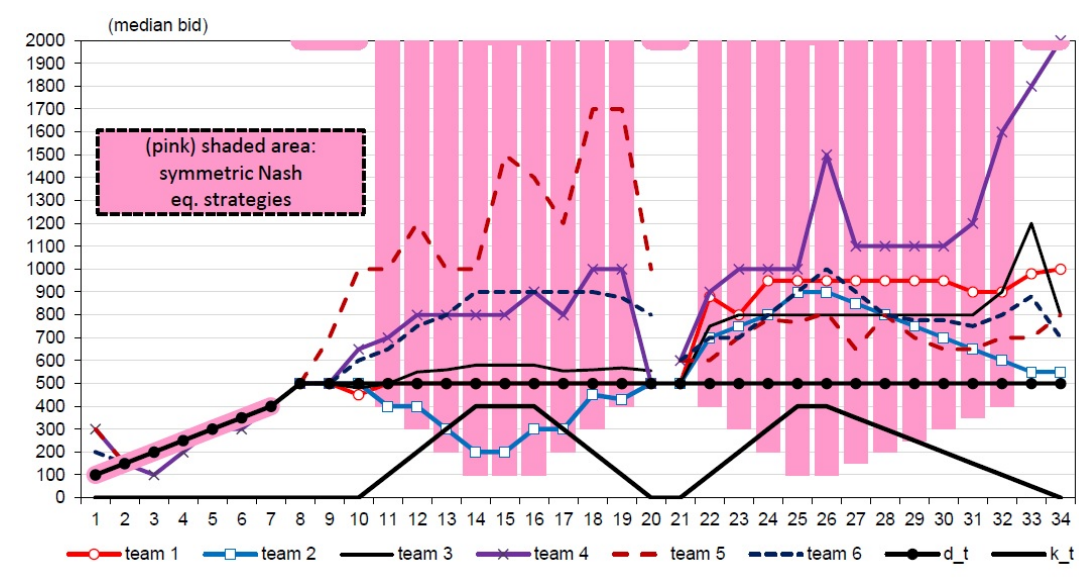

\footnotetext{
${ }^{14}$ Shino [17] refers to two completely opposing hypotheses regarding the effects of negative interest rate policy on fixed-rate operation: (i) to shift the demand curve left [the market view], or (ii) to make the objective functions less satiated [a view derived from Shino [16]] and argues that the latter is empirically supported.
} 
Figure 13: Median bids of each team in Scenario 2

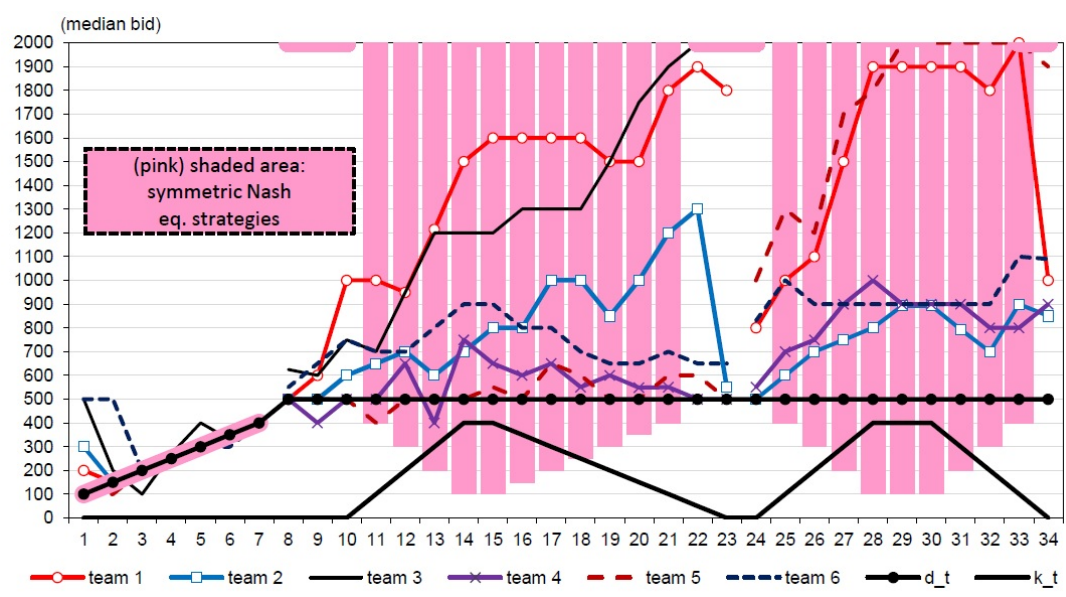

Figure 14: Average and median aggregate bids in Scenario 1

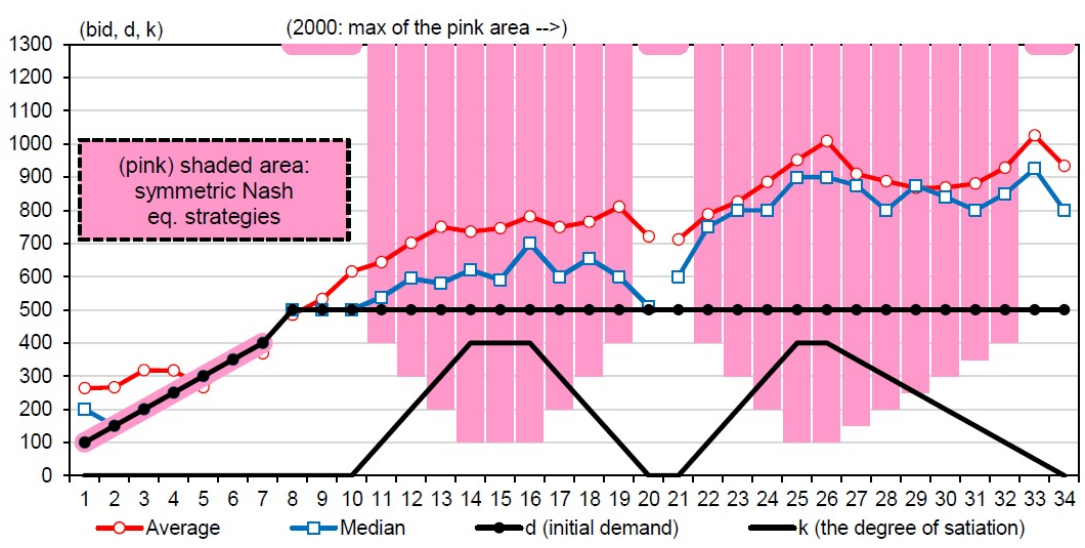

Figure 15: Average and median aggregate bids in Scenario 2

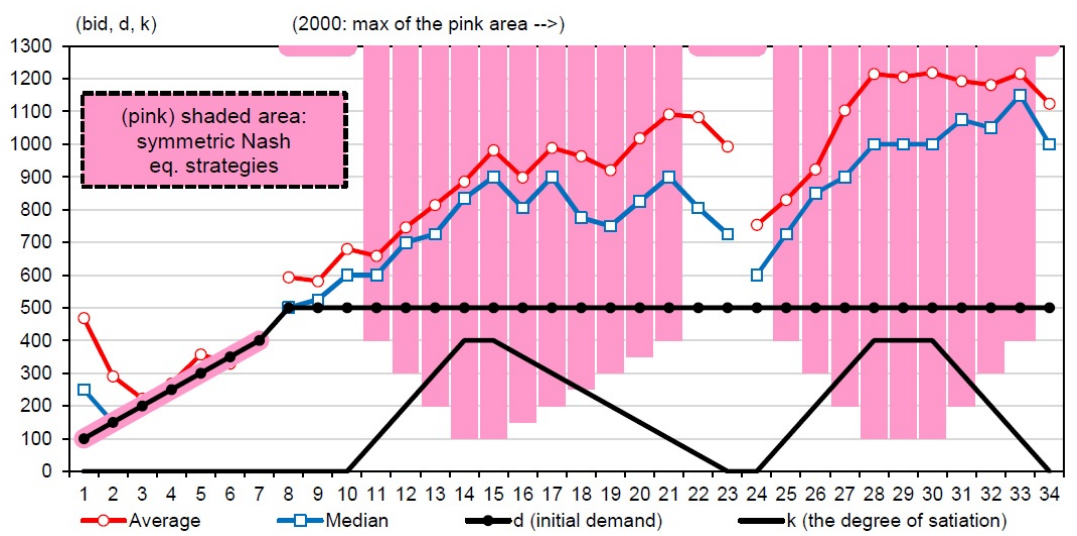




\section{References}

[1] Ayuso, J., and Repullo, R. (2001), Why Did the Banks Overbid? An Empirical Model of the Fixed-Rate Tenders of the European Central Bank, Journal of International Money and Finance 20, 857-870.

[2] Ayuso, J., and Repullo, R. (2003), A Model of the Open Market Operations of the European Central Bank, The Economic Journal 113, 883-902.

[3] Bank of Japan (2008), Establishment of Principal Terms and Conditions of Complementary Deposit Facility as a Temporary Measure to Facilitate Supplying of Funds.

[4] Bank of Japan (2011), Financial Markets Report (February 2011).

[5] Bank of Japan (2016), Money Market Operations in Fiscal 2015.

[6] Bierbaum, J. and Grimm, V. (2006), Selling Shares to Retail Investors: Auction vs. Fixed Price, Review of Economic Design, 10, 85-112.

[7] Breitung, J., and Nautz, D. (2001), The Empirical Performance of the ECB's Repo Auctions: Evidence from Aggregated and Individual Bidding Data, Journal of International Money and Finance, 20, 839-856.

[8] Catalao-Lopes, M. (2010), Fixed- and Variable-Rate Tenders in the Management of Liquidity by the Eurosystem: Implications of the Recent Credit Crisis, International Journal of Central Banking June 2010, 539-549.

[9] European Central Bank (2000), The Switch to Variable Rate Tenders in the Main Refinancing Operations, Monthly Bulletin July, 37-42.

[10] Ewerhart, C., Cassola, N., and Valla, N. (2012), Overbidding in Fixed Rate Tenders: The Role of Exposure Risk, Journal of Banking and Finance 36, 539-549.

[11] Grimm, V., Kovarik, J., and Ponti, G. (2008), Fixed Price plus Rationing: An Experiment, Experimental Economics 11, 402-422.

[12] Kagel, J. H., and Roth, A. E. (2016), The Handbook of Experimental Economics, Volume 2, Princeton University Press.

[13] Lusk, J., and Shogren, J. (2007), Experimental Auctions: Methods and Applications in Economic and Marketing Research, Cambridge University Press.

[14] Nautz, D., and Oechssler, J. (2003), The Repo Auctions of the European Central Bank and the Vanishing Quota Puzzle, Scandinavian Journal of Economics 105(2), 207-220.

[15] Nautz, D., and Oechssler, J. (2006), Overbidding in Fixed Rate Tenders - an Empirical Assessment of Alternative Explanations, European Economic Review 50, 631-646. 
[16] Shino, J. (2013), A Positive Theory of Fixed-Rate Funds-Supplying Operations in an Accommodative Financial Environment, Journal of International Money and Finance 32, 595-610.

[17] Shino, J. (2019). Effects of Negative Interest Rate Policy on Bids in Fixed-Rate Operations, Waseda Global Forum, 15, 57-80. 